BMC

Microbiology

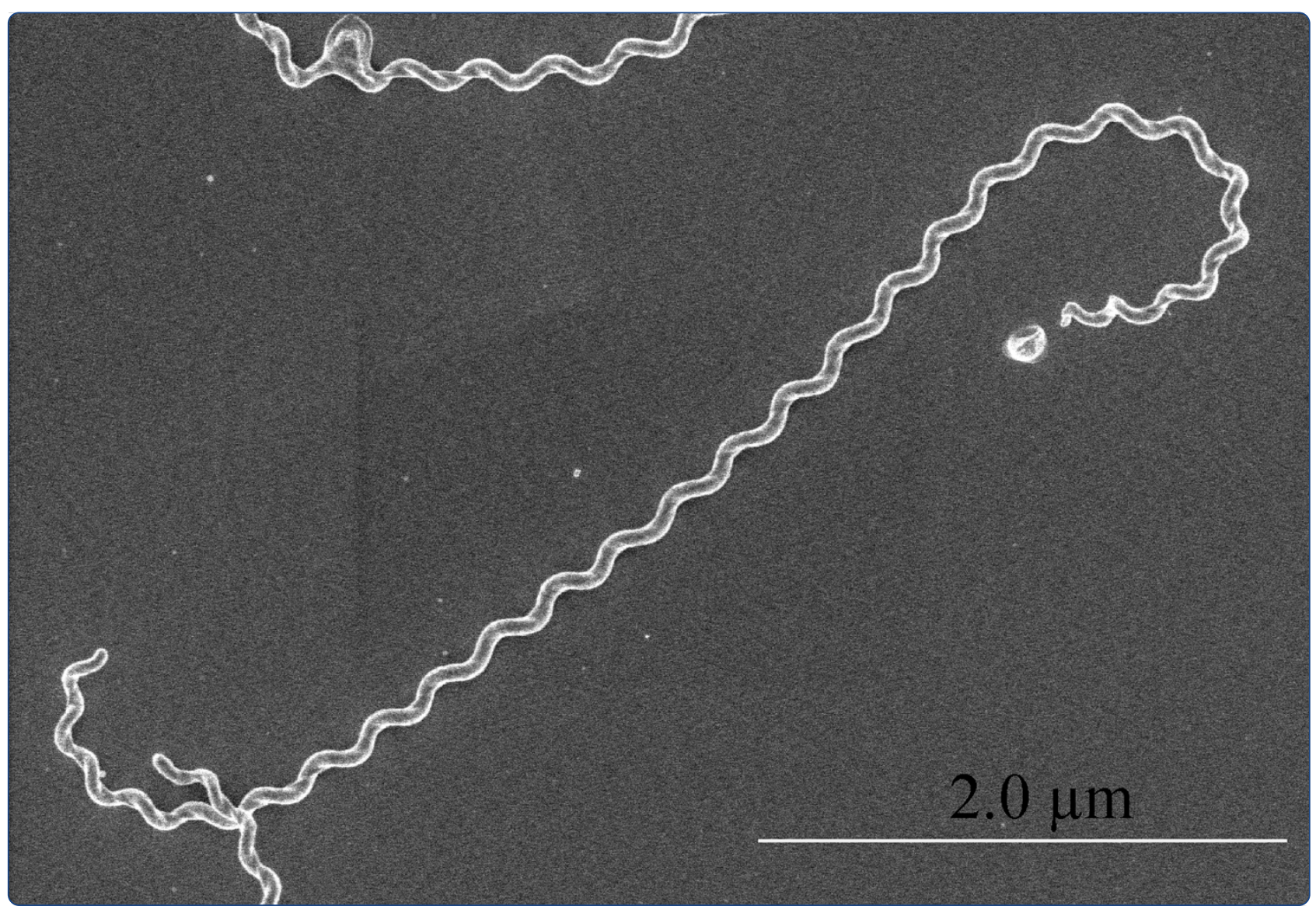

Characterization of the Bat proteins in the oxidative stress response of Leptospira biflexa

Stewart et al.

() Biomed Central 


\title{
Characterization of the Bat proteins in the oxidative stress response of Leptospira biflexa
}

\author{
Philip E Stewart ${ }^{1 *}$, James A Carroll ${ }^{2}$, David W Dorward ${ }^{3}$, Hunter H Stone ${ }^{1}$, Amit Sarkarr ${ }^{1}$, Mathieu Picardeau ${ }^{4}$ \\ and Patricia A Rosa ${ }^{1}$
}

\begin{abstract}
Background: Leptospires lack many of the homologs for oxidative defense present in other bacteria, but do encode homologs of the Bacteriodes aerotolerance (Bat) proteins, which have been proposed to fulfill this function. Bat homologs have been identified in all families of the phylum Spirochaetes, yet a specific function for these proteins has not been experimentally demonstrated.

Results: We investigated the contribution of the Bat proteins in the model organism Leptospira biflexa for their potential contributions to growth rate, morphology and protection against oxidative challenges. A genetically engineered mutant strain in which all bat ORFs were deleted did not exhibit altered growth rate or morphology, relative to the wild-type strain. Nor could we demonstrate a protective role for the Bat proteins in coping with various oxidative stresses. Further, pre-exposing L. biflexa to sublethal levels of reactive oxygen species did not appear to induce a general oxidative stress response, in contrast to what has been shown in other bacterial species. Differential proteomic analysis of the wild-type and mutant strains detected changes in the abundance of a single protein only - HtpG, which is encoded by the gene immediately downstream of the bat loci.

Conclusion: The data presented here do not support a protective role for the Leptospira Bat proteins in directly coping with oxidative stress as previously proposed. L. biflexa is relatively sensitive to reactive oxygen species such as superoxide and $\mathrm{H}_{2} \mathrm{O}_{2}$, suggesting that this spirochete lacks a strong, protective defense against oxidative damage despite being a strict aerobe.
\end{abstract}

\section{Background}

Molecular oxygen freely diffuses across bacterial membranes and can give rise to damaging reactive oxygen species (ROS) such as superoxide radicals $\left(\mathrm{O}_{2}^{-}\right)$, hydrogen peroxide $\left(\mathrm{H}_{2} \mathrm{O}_{2}\right)$, and hydroxyl radicals $(\mathrm{OH} \bullet)$. These highly reactive molecules lead to a variety of harmful effects within the bacterial cell, including inactivation of Fe-S-containing proteins and damage to DNA and to lipids, in some bacteria. For aerobic microorganisms the presence of these toxic species is by nature unavoidable and they have therefore evolved a variety of protective enzymes to preemptively detoxify ROS.

The enteric bacteria have been intensively studied for their response to ROS (recently reviewed by [1]). In

\footnotetext{
* Correspondence: pestewart@niaid.nih.gov

'Laboratory of Zoonotic Pathogens, Rocky Mountain Laboratories, National Institute of Allergy and Infectious Diseases, National Institutes of Health, 903 South 4th St, Hamilton, Montana 59840, US

Full list of author information is available at the end of the article
}

contrast, leptospires lack a number of the enzymes used by enteric bacteria to combat oxidative damage [2] and are also more susceptible to $\mathrm{H}_{2} \mathrm{O}_{2}$-mediated killing than other microorganisms [3]. Nascimento and colleagues speculated that the Bat proteins of L. interrogans might partially compensate for the shortage of oxidative stress proteins by providing an additional line of defense against oxidative damage [2].

The Bat proteins were first identified by Tang and coworkers in a transposon mutagenesis screen of the anaerobe Bacteroides fragilis [4]. The transposon inserted into the fourth of five contiguous open reading frames and resulted in reduced levels of aerotolerance and pathogenicity. The genes were designated bat, for Bacteriodes aerotolerance genes, and were shown to comprise an operon. The mutant phenotype could be partially complemented by the addition of reducing agents and the Bat proteins were proposed to directly reduce oxidatively-damaged proteins in the periplasm or, alternatively, to help create a

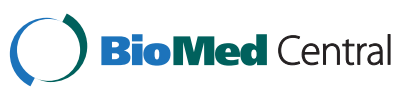


reduced environment in the periplasm by exporting reducing power equivalents. Interestingly, anaerobic growth did not restore the growth rate to that of wild-type and the addition of reducing agents also increased growth of the wild-type strain, although not as dramatically as it did for the mutant.

Recently, two bat homologs in Francisella tularensis were inactivated and the bat mutants were shown to have a reduced ability to replicate in macrophage cells and were also attenuated for virulence in a mouse model [5]. The specific function of the Bat proteins, however, was not determined in F. tularensis. Genome sequences have identified homologs in a wide variety of other prokaryotes, including all families that comprise the phylum Spirochaetes (Brachyspiraceae, Leptospiraceae, and Spirochaetaceae). Although conserved in all branches of the Spirochaetes, the number and combination of bat homologs vary by species. However, the function of the Bat proteins in spirochetes or in any other species has not been elucidated.

Although pathogenic leptospires also contain bat homologs and are more resistant to peroxide exposure than the saprophyte L. biflexa $[3,6]$, the pathogenic spp. are notoriously recalcitrant to targeted allelic exchange. Since L. biflexa is more amenable to genetic manipulation than pathogenic species, it serves as a model organism for genetic studies in leptospires. Therefore, we used L. biflexa to investigate the function of the Bat proteins and to better understand the response of leptospires to oxidative stress. Here, we report the engineered deletion of the three contiguous L. biflexa bat genes and characterization of the mutant phenotype and oxidative stress response.

\section{Results}

The bat genes are distributed throughout the Spirochaetes and encode conserved protein motifs

Homologs of the bat genes are present in each family of the Spirochaetes (Additional file 1: Figure S1), although not in all species. In contrast to the 5 genes present in $B$. fragilis, L. biflexa contains 3 bat genes and the pathogenic leptospires contain 4 [2,7-9]. However, the batB and batC genes are fused in L. biflexa, which does not appear to be the case for the pathogenic species, and explains the discrepancy in gene number. Fusions of bat coding regions also appear to have occurred in Borrelia burgdorferi and Spirochaeta thermophila (Additional file 1: Figure S1) and were also reported for F. tularensis type A strain Schu S4 [5].

Analysis of BatA and BatB sequences identified motifs predicted to mediate protein-protein interactions, (Figure 1). The presence of these motifs suggest that Bat proteins may interact with each other to form a large protein complex. All three proteins are predicted to contain multiple trans-membrane helices, also predicted for the $B$. fragilis homologs, and BatD possesses a predicted signal sequence for export, suggesting that these proteins may associate with either the inner or outer membrane of L. biflexa.

\section{Deletion of bat genes}

The L. biflexa bat genes are located within a contiguous stretch of 11 genes on chromosome II that are transcriptionally oriented in the same direction (Figure 2A). Two different mutations were engineered using allelic

Figure 1 Amino acid motifs in the Bat proteins of L. biflexa. The vWF and TPR domains are conserved among Bat homologs and have been
$\begin{aligned} & \text { proposed to facilitate formation of a large Bat protein complex [4]. The vWF domains identified in Bat proteins contain metal ion-dependent } \\ & \text { adhesion sites (MIDAS) shown to bind metal ions [10] and the domain overall is thought to mediate protein-protein interactions [11]. The TPR } \\ & \text { domain of BatB consists of a repeated amino acid motif previously shown to form a tertiary scaffold structure for multiprotein complex formation } \\ & \text { (reviewed in [12]). These domains, along with the presence of multiple transmembrane helices and a signal sequence identified in BatD, suggest } \\ & \text { that the Bat proteins form a complex associated with either the inner or outer membrane of L. biflexa. }\end{aligned}$
$=$ = Signal peptide (SP)
= Transmembrane Helix


replacement with the kanamycin-resistance cassette to delete either batA alone or batABD together; flanking genes were left intact. Three mutant clones from each transformation were shown to have lost the corresponding bat loci by Southern blot analysis of genomic DNA (Figure 2B). PCR analysis also confirmed the presence of the antibiotic-resistance gene (kan) and flanking genes, but bat loci were absent, as expected (data not shown). A single transformant of each type was randomly chosen for further characterization.

\section{Transcript analyses indicate independent promoters in the bat gene cluster}

Transcript levels of bat genes and other ORFs were assessed by qRT-PCR with RNA from wild-type (WT), $\triangle b a t A$ and $\triangle b a t A B D$ strains cultured in vitro (Figure 3). Transcript from the bat genes is present in the WT strain but undetectable in the $\triangle$ bat $A B D$ mutant, as expected. In the $\triangle b a t A$ mutant strain, only the bat $A$ transcript is undetectable, but transcripts from the downstream ORFs, including batB and batD, were detected. Although the arrangement of the 11 genes suggest they may be co-transcribed in an operon, the deletion of the bat genes does not eliminate transcript from the downstream ORFs and we hypothesize that each gene has an independent promoter. Interestingly, even ORFs immediately downstream of the deleted genes had observable levels of transcript, even though their promoter regions were most likely located in the deleted sequences. However, the levels of transcript from the downstream genes were significantly lower in the mutant strains compared to transcript levels in the WT: $h t p G$ transcript levels were 3.7-fold lower in the $\triangle$ bat $A B D$ strain, and batB transcript levels were $>12$ fold lower in the $\triangle b a t A$ mutant.

\section{Morphology and growth rate of bat mutants are equivalent to wild-type}

The signal sequence of BatD suggests a periplasmic or membrane-associated location for at least one member of this protein family. We therefore examined whether the absence of Bat proteins affected cellular shape or structure. L. biflexa morphology was assessed by scanning and transmission electron microscopy, including negative stains and freeze-substitution fixation to retain a more native state of the cells. As shown in
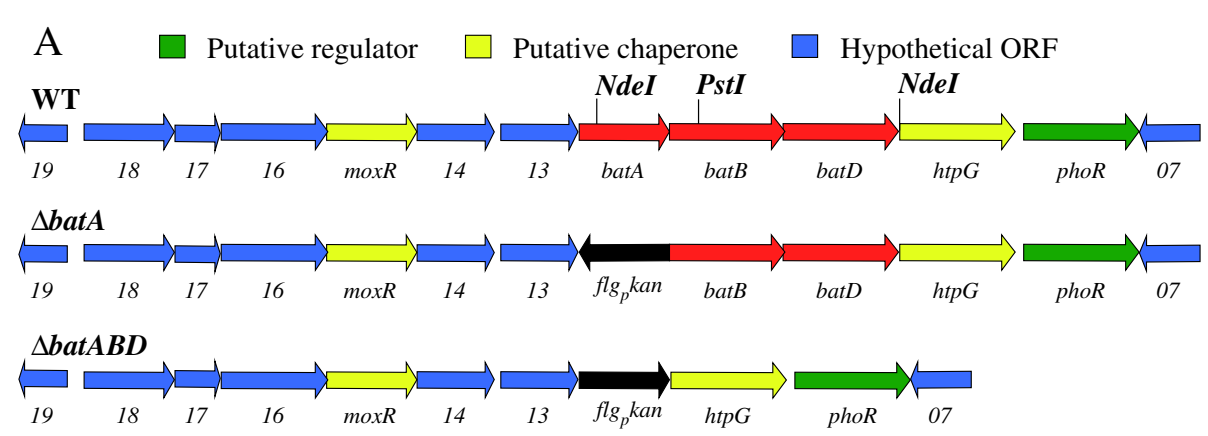

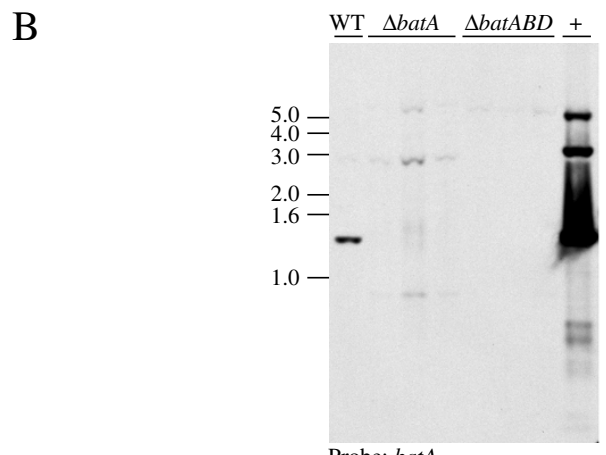

Probe: batA

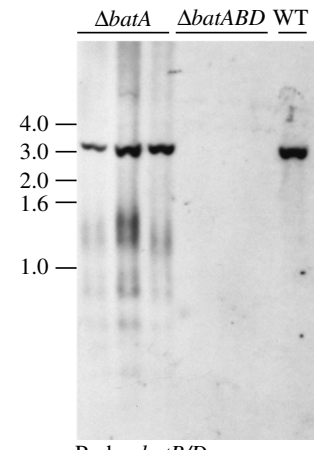

Probe: $b a t B / D$

Figure 2 Gene organization in wild-type and mutant strains of $\boldsymbol{L}$. biflexa. (A) Genetic organization of bat genes and flanking genes on chromosome II of L. biflexa (not drawn to scale). The corresponding deleted regions in mutant strains are depicted with the respective bat genes replaced by the kanamycin-resistance cassette [13]. (B) Southern blot analysis of L. biflexa strains confirms the absence of the respective bat genes in mutant strains. Genomic DNA for the Southern blot was double-digested with restriction endonucleases Ndel and Pstl. Three independently isolated transformants from each mutant were compared to wild-type and hybridized with either a labeled batA fragment or with a labeled fragment spanning batB to batD. The weak signal observed at $\sim 3 \mathrm{~kb}$ in the batA mutant strains hybridized with the batA probe is likely due to cross-hybridization with batB. +, purified plasmid DNA from E. coli with a cloned region of L. biflexa DNA containing batABD. 


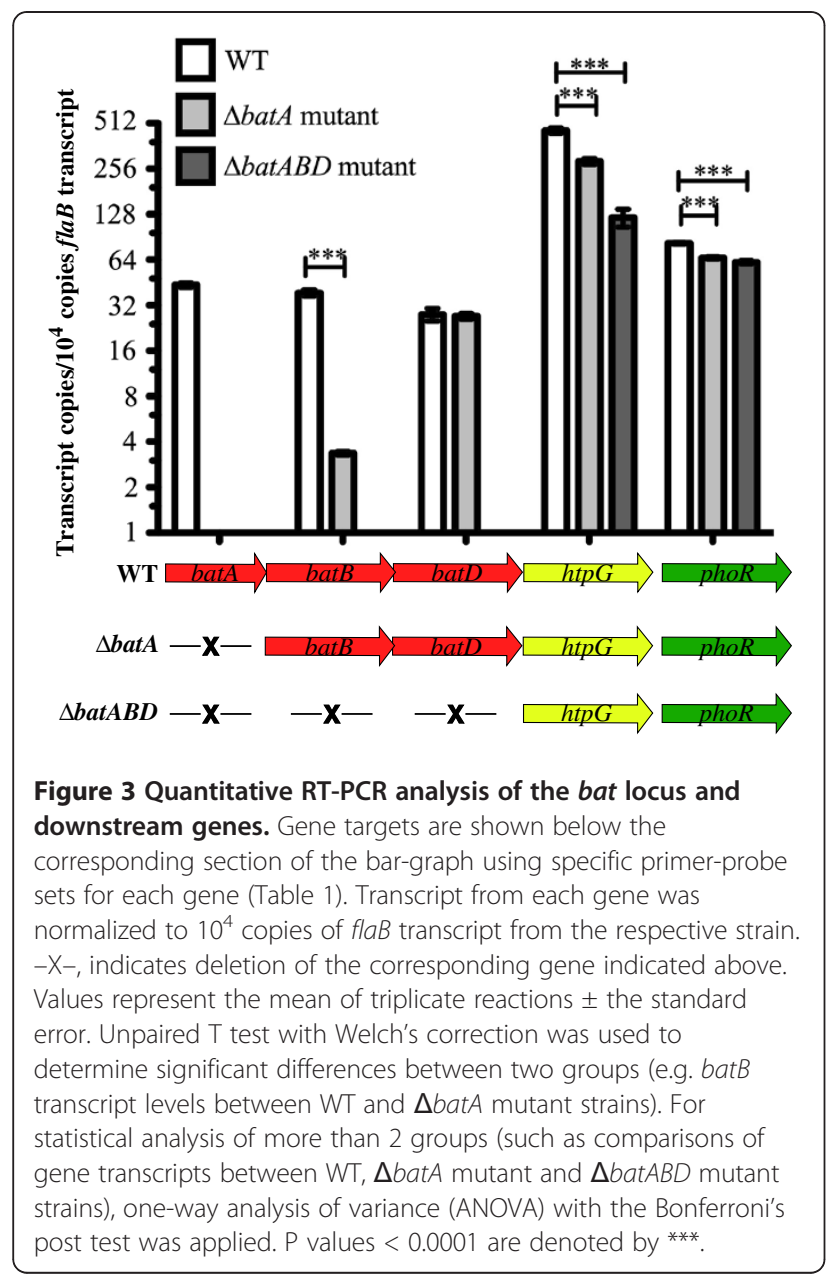

representative images in Figure 4A, no morphological or ultrastructural differences were observed between the WT and mutant strains by any of these analyses.

Growth rates of WT, $\triangle$ batA, and $\triangle$ batABD strains were compared during in vitro cultivation in EMJH liquid medium and also for colony formation on solid EMJH medium. No significant differences in growth rate were observed when cultured in liquid medium, regardless of whether the cultures were aerated or static (Figure 4B). Colony morphology and rate of formation were similar among all strains (data not shown).

As the mutant strains did not display an obvious growth defect compared to WT, we assessed the growth dynamics of both parent and mutant when cultured together in the same medium (Figure $4 \mathrm{C}$ ). WT and $\triangle$ bat- $A B D$ strains were co-inoculated into the same cultures (performed in triplicate) and assessed daily to determine if population ratios changed over time. As shown in Figure $4 C$, relative proportions of each strain did not change significantly over time and this was statistically confirmed by two-way Analysis of Variance (ANOVA) with the Bonferroni post-test. Therefore, the
Bat proteins do not significantly affect $L$. biflexa growth, either in pure culture or when the mutant is mixed with an equal density of WT cells.

\section{Deletion of bat genes does not alter tolerance to oxidative stress}

Previous researchers speculated that Bat proteins might provide a mechanism for coping with oxidative stress $[2,4,14]$. Therefore, we compared the resistance of WT and $\triangle b a t A B D$ strains to various concentrations of hydrogen peroxide and a more stable organic peroxide (tert-Butyl hydroperoxide), and to superoxide. We utilized the $\Delta$ bat$A B D$ mutant in this comparison as we hypothesized that it would have a similar or greater phenotype than the single gene deletion in the $\triangle b a t A$ strain. Both the WT and the $\triangle$ bat $A B D$ strain exhibited comparable levels of susceptibility to all ROS tested, with greater than $90 \%$ killing when exposed to $10 \mu \mathrm{M}$ concentrations of $\mathrm{H}_{2} \mathrm{O}_{2}$, but resistant to $1 \mu \mathrm{M}$ (Figure 5A). Similarly, when $L$. biflexa strains were exposed to paraquat, a redox-cycling compound that generates superoxide, WT and mutant strains displayed similar susceptibility to paraquat concentrations (Figure 5B).

\section{L. biflexa lacks an inducible stress response to ROS}

Bacteria such as E. coli and Salmonella typhimurium exhibit an inducible response to oxidative agents $[15,16]$. When activated by exposure to sublethal levels of oxidizing agents, this stress response allows some bacteria to induce enzymes that allow the cell to survive otherwise lethal levels of oxidants. As the Bat proteins did not aid in resistance to oxidative stress, we next tested whether their function may relate to sensing oxidizing agents and inducing a specific stress response in Leptospira. Midto-late log phase cultures were incubated in sublethal concentrations of either $\mathrm{H}_{2} \mathrm{O}_{2}(1 \mu \mathrm{M})$ or paraquat $(0.5 \mu \mathrm{M})$ to potentially induce an oxidative stress response. Cultures were then subjected to various concentrations of ROS that included normally lethal levels, further incubated, and viable bacteria enumerated (Figure 6). Surprisingly, both pretreated and untreated cells were sensitive to similar concentrations of ROS, indicating that $L$. biflexa does not exhibit an inducible response to either $\mathrm{H}_{2} \mathrm{O}_{2}$ or superoxide. The $\triangle$ batABD mutant strain was likewise treated but did not show any differences from the WT with either pretreatment (data not shown).

\section{Differential proteomic analysis of WT and mutant strains detected changes in HtpG levels among membrane- associated proteins}

Differential in-gel electrophoresis (DIGE) of WT versus $\triangle$ bat $A B D$ mutant protein samples was used to identify changes in protein levels between strains (Figure 7). Protein samples were separated into membrane-associated 

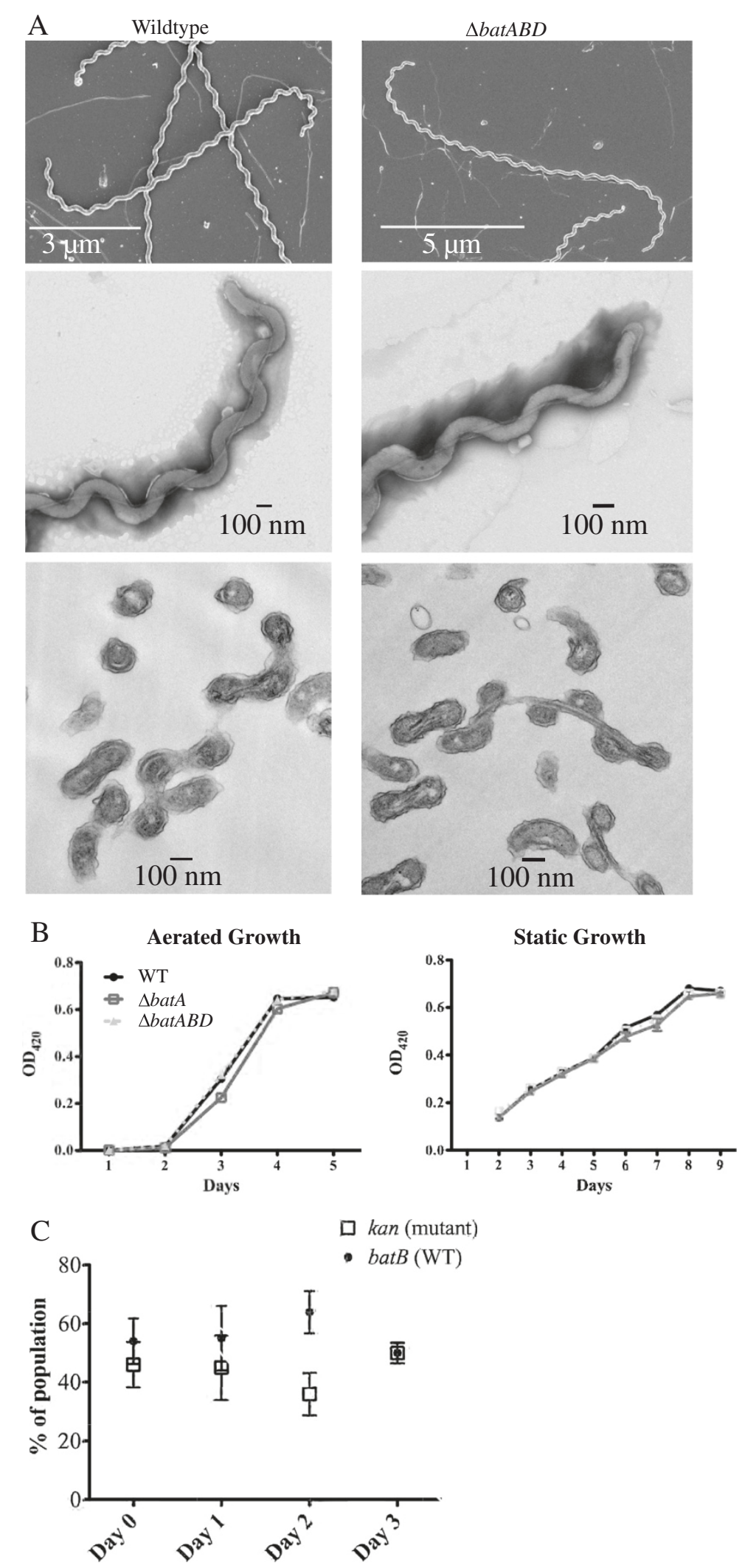

Figure 4 (See legend on next page.) 
(See figure on previous page.)

Figure 4 Deletion of bat loci does not alter morphology or growth of L. biflexa. (A) Electron micrographs of WT and mutant L. biflexa strains. No difference was observed in the morphology of the mutant strains relative to the WT (batA images not shown). Top panel - SEM images of L. biflexa strains; middle panel - TEM negative stains of spirochetes; bottom panels - TEM cross-section images of spirochetes. (B) Growth curves of L. biflexa strains grown with shaking (aerated cultures) or without shaking (static cultures). Data represent the mean \pm the standard error calculated from quadruplicate cultures. (C) Results of co-growth of wild-type and $\triangle$ batABD mutant in the same culture. Aerated cultures were sampled daily to determine the percent of wild-type cells $(\cdot)$ and of $\triangle b a t A B D$ mutant cells $(\square)$ in the population. Both strains remained at about the same percentage of the population throughout the timecourse, indicating that the $\triangle$ batABD mutant did not show a competitive disadvantage during in vitro cultivation. Variations over time were not statistically significant as determined by 2-way ANOVA. Data represent the mean \pm the standard error calculated from triplicate cultures.

and soluble fractions. No differences were observed in the soluble fractions (data not shown) but in the membrane-associated comparison, a single protein was observed to vary between samples (Figure 7, white oval). The region encompassing the protein was excised from the gel, trypsin-digested and identified by mass spectrometry as HtpG (40 peptides detected, 61\% coverage), which is encoded by the gene immediately downstream of batD (Figure 2A). The HtpG protein appeared as several closely migrating spots, with the main mass of protein indicated in Figure 7. Protein levels were higher in the WT compared to the $\triangle b a t A B D$ strain, and differences for each spot ranged from 2.7 -fold for the minor spot to greater than 4-fold higher for the main protein spot. This difference in HtpG protein levels approximately corresponds to the difference observed in transcript levels by qRT-PCR between WT and $\triangle$ bat $A B D$ strains (Figure 3). The Bat proteins were not identified by this approach. Bat protein levels may be relatively low and the fold change between mutant and WT may not be significant enough to be detected by the conditions tested here. For example, transcript levels of $h t p G$ in the WT strain are more than 10-fold higher than any of the bat transcripts (Figure 3).

\section{Discussion}

Bat homologs are present in all families of the Spirochaetales (Additional file 1: Figure S1), despite the vast evolutionary divergence noted in this order [17]. The retention of these proteins suggests they confer an evolutionary advantage to spirochetes, even though the environment and life cycle of these bacteria are incredibly diverse, ranging from free-living aerobic saprophytes (L. biflexa) and anaerobic thermophiles (Spirochaeta thermophila) to mammalian pathogens ( $L$. interrogans and B. burgdorferi). L. borgpetersenii, purportedly undergoing genome reduction, retains the same number and order of bat genes as L. interrogans [7], again suggesting the Bat proteins provide an important function that prevents their elimination even in a decaying genome. One spirochete appears to be an exception to this theory the obligate human pathogen and syphilis agent, Treponema pallidum, in which we were unable to identify any Bat homologs.
In addition to the wide-spread distribution of the Bat proteins in the Spirochaetales, MoxR and HtpG are also encoded in many spirochete genomes (data not shown). The MoxR chaperone is postulated to coordinate the metal ion into the Bat proteins MIDAS domain (Figure 1) [18]. In the sequenced Leptospira genomes, moxR and $h t p G$ are located in the same contiguous gene cluster as the bats (Figure 2A) [2,7-9]. However, Dieppedale et al. inactivated $\operatorname{moxR}$ in $F$. tularensis and their proteomic comparisons of wild-type to the moxR mutant did not identify changes in Bat protein levels [5]. HtpG is a homolog of the eukaryotic heat shock protein Hsp90, but its function in bacteria is unclear and it has been reported to have different roles in different prokaryotes [19-22]. The arrangement of the 11 tandem ORFs in this cluster suggest they potentially form a large operon, but qRT-PCR analyses detected transcript from the ORFs downstream of the deleted bat genes. The presence of transcript from the downstream ORFs, regardless of the orientation of the inserted kanamycinresistance cassette, implies that these genes can be independently transcribed (Figure 3 ). These data do not rule out the possibility of an additional promoter that drives expression of all 11 genes in an operon, but do support independent promoters for the genes downstream of the deleted regions.

Somewhat surprisingly, transcript from genes immediately following the deletion site had detectable levels of transcript, although these levels were significantly lower than WT levels. Specifically, transcript of batB was detected in the $\triangle b a t A$ strain, even though the endogenous promoter is likely to be located in the deleted batA gene. However, batB transcript levels are over 10 -fold lower in the $\triangle b a t A$ strain compared to wild-type, suggesting that the kanamycin-resistance cassette upstream of batB may provide a weak, fortuitous promoter sequence. A similar result was also observed for $h t p G$ transcript in the $\Delta b a t$ $A B D$ strain; presumably, the $h t p G$ promoter would be located in the deleted region. The borrelial flgB promoter used to drive kan expression in the deletion of batABD is oriented in the same transcriptional direction as the endogenous genes (specifically, $h t p G$ ) and read-through may account for the $h t p G$ transcript detected, albeit at a lower level than the endogenous promoter would produce. 

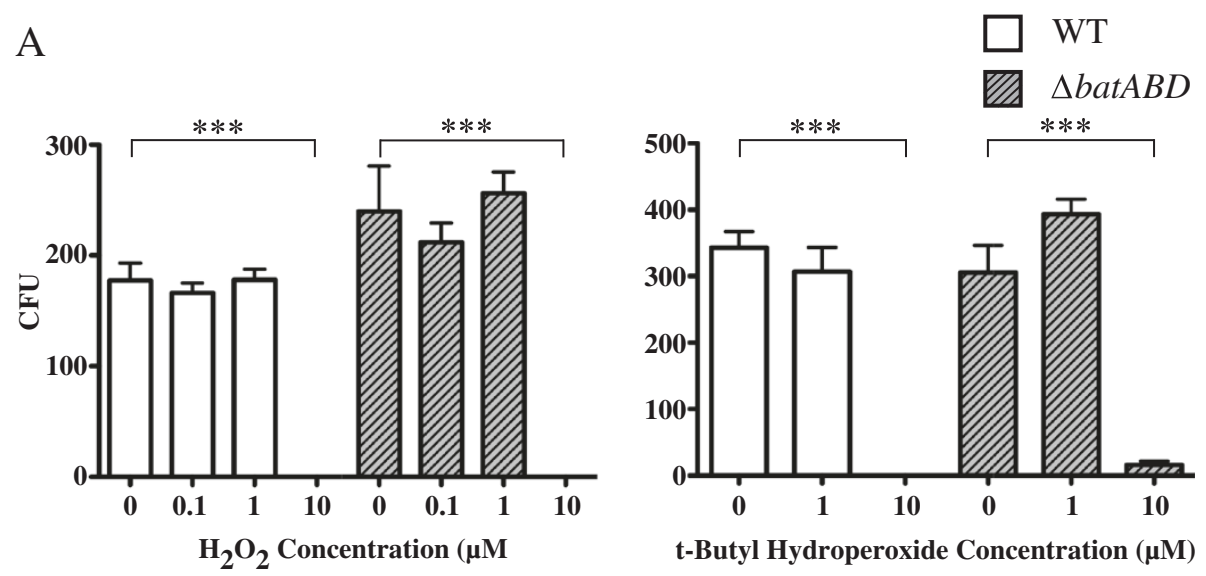

$\mathrm{B}$

WT

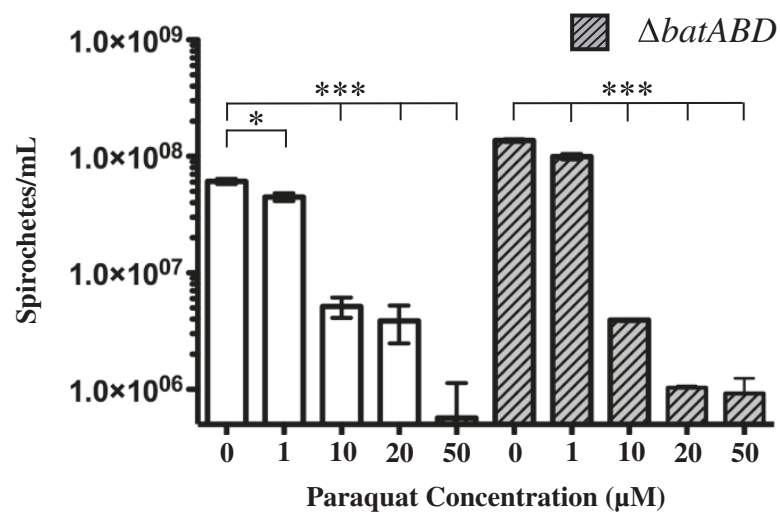

Figure 5 Susceptibility of $L$. biflexa strains to ROS. (A) WT or $\triangle$ batABD strains were exposed to varying concentrations of either $\mathrm{H}_{2} \mathrm{O}_{2}$ (left panel) or to the more stable organoperoxide, tert-Butyl hydroperoxide (right panel) and viability determined by counting CFUs after plating. (B) Effect of paraquat concentrations on L. biflexa. Twenty four hours after exposure to varying concentrations of the superoxide generator paraquat, viability was assessed by counting motile spirochetes using darkfield microscopy. One-way ANOVA was used to determine significant differences between treated and untreated samples ( ${ }^{*}$ denotes $P$ value $<0.05$, *** denotes $P$ value $<0.0001$ ). Values represent the mean \pm the standard error.

The presence of a signal sequence, transmembrane helices and motifs for protein-protein interactions, also conserved in the Bat proteins of Leptospira (Figure 1), led Tang et al. to propose that the Bat proteins of B. fragilis formed a complex in the periplasm [4]. Despite their putative cellular location, growth rate and morphology of L. biflexa were unaffected by the loss of these proteins (Figure 4). Nor could we demonstrate a protective role for the Bat proteins in coping with oxidative stress, as initially proposed for B. fragilis and subsequently hypothesized for other spirochetes [2,14]. The wild-type and $\triangle$ bat $A B D$ mutant were equally susceptible to oxidative challenge by both peroxides and the superoxide generator paraquat (Figure 5), indicating that the Bat proteins do not contribute to $L$. biflexa's limited ability to cope with oxidative damage. However, the lack of an observable phenotype for the bat mutants may relate to in vitro growth where the transcript levels for these genes is quite low relative to flaB or $h t p G$ transcript levels (Figure 3). It is conceivable that bat expression may increase under specific in vivo conditions of which we are unaware. Various microarray studies, however, did not detect any significant changes in bat transcript levels in pathogenic leptospires when in vitro conditions were altered to mimic in vivo environments [23-29].

We also examined the potential contribution of the Bat proteins to sensing ROS and inducing an oxidative stress response in $L$. biflexa. Enteric bacteria such as E. coli and Salmonella typhimurium have well-characterized oxidative stress responses that can be induced by the addition of sublethal levels of peroxide [15,16] or superoxide [30-32]. However, pretreatment of exponentially growing $L$. biflexa cultures with either $1 \mu \mathrm{M} \mathrm{H}_{2} \mathrm{O}_{2}$ or $0.5 \mu \mathrm{M}$ paraquat failed to confer a higher level of resistance to ROS when 

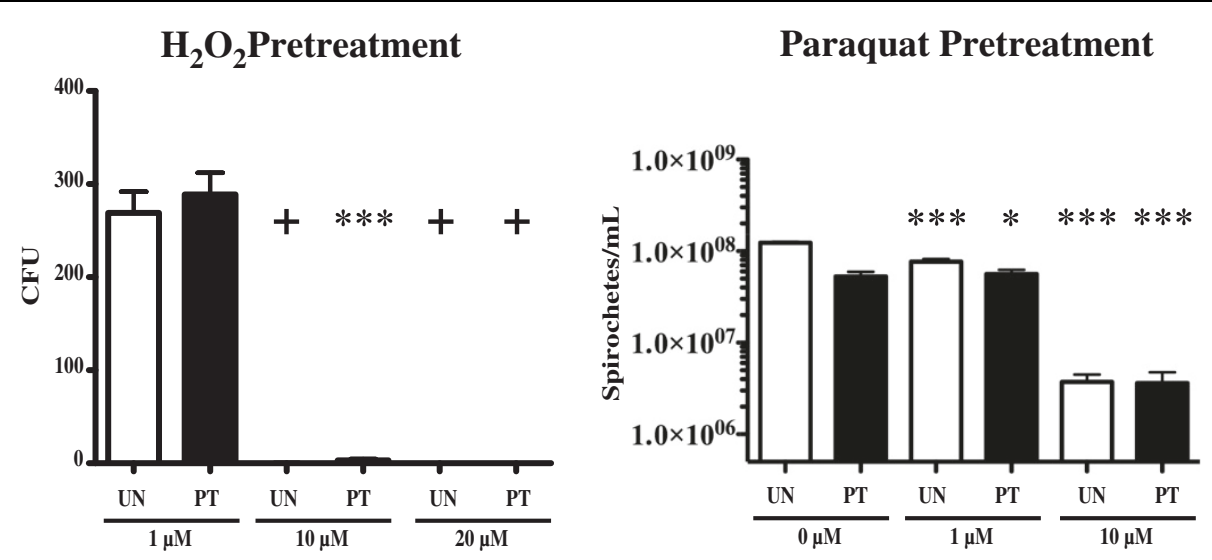

Figure 6 Effect of ROS pretreatment on viability of L. biflexa exposed to lethal concentrations of ROS. WT L. biflexa was pretreated with sub-lethal levels of $\mathrm{H}_{2} \mathrm{O}_{2}$ (left panel) or superoxide generated by paraquat (right panel) and compared to samples that were not pretreated. Subsequently, cultures were exposed to varying concentrations of $\mathrm{ROS}$ and viability assessed by either colony counts on solid medium $\left(\mathrm{H}_{2} \mathrm{O}_{2}\right)$ or by enumerating motile spirochetes using a Petroff-Hauser counting chamber and darkfield microscopy (paraquat). UN, untreated cells; PT, pretreated cells. One-way ANOVA was used to determine significant differences between treated and the respective untreated samples (* denotes $P$ value $<0.05,{ }^{* * *}$ denotes $P$ value $<0.0001$,). Values represent the mean \pm the standard error. + denotes that statistical analysis was not performed because the value was zero and a standard error could not be calculated.

subsequently challenged with lethal levels (Figure 6). Therefore, it appears that L. biflexa does not have the same capability as enteric bacteria of inducing an oxidative stress response, at least under the conditions tested. L. biflexa lacks homologs for the two main regulators of the oxidative stress response in enteric bacteria (SoxR and OxyR), in support of this conclusion. However, Leptospira spp. do possess a PerR homolog (LEPBI_I2461 in L. biflexa), a negative regulator of peroxide defense first characterized in Gram positive bacteria (reviewed in [33]). Lo et al. reported a PerR transposon mutant of L. interrogans that resulted in an 8-fold increase in resistance to hydrogen peroxide over the wild-type [25]. However, microarray data of this mutant did not report any significant changes in bat transcript, suggesting that these genes may not be under the regulatory control of PerR. It is still possible that the Bat proteins are involved in sensing ROS, but the cellular response they may direct remains enigmatic.

Surprisingly, even wild-type L. biflexa is highly susceptible to oxidative stress compared to B. burgdorferi $(10 \mu \mathrm{M}$ vs. $10 \mathrm{mM}$, respectively, for t-Butyl hydroperoxide) [34] or E. coli [35]. The relative susceptibility of L. biflexa to oxidative damage may be due to the absence of some proteins capable of detoxifying ROS or repairing damaged proteins. For example, L. biflexa does not have recognizable homologs of glutathione reductase, thioredoxin 2, Ferric reductase, and others. However, L. biflexa does possess both superoxide dismutase (Sod) and KatG (a Hydroperoxidase I enzyme), two enzymes widely conserved among aerobic organisms for defense against ROS. Sod catalyzes the reduction of $\mathrm{O}_{2}^{-}$to $\mathrm{H}_{2} \mathrm{O}_{2}$ and $\mathrm{O}_{2}$. Hydrogen peroxide is itself an oxidant that freely diffuses across membranes and can give rise to the highly reactive hydroxyl radical. Therefore, aerobic cells require a mechanism for detoxifying $\mathrm{H}_{2} \mathrm{O}_{2}$. Catalase or peroxidase enzymes usually fulfill this cellular function and a gene encoding KatG, which can have either activity, has been identified in the L. biflexa genome (LEPBI_I2495). Since catalase activity has not been detected in L. biflexa strains but peroxidase activity has [36-40], it seems likely that KatG is a peroxidase and provides a mechanism by which $L$. biflexa detoxifies $\mathrm{H}_{2} \mathrm{O}_{2}$, albeit not very effectively. L. biflexa also possesses alkyl hydroperoxide reductase homologs (LEPBI_I3008 \& LEPBI_I3009) that may also detoxify $\mathrm{H}_{2} \mathrm{O}_{2}$. Superoxide dismutase may play an essential role in L. biflexa's defense against oxidative stress, as we were unable to inactivate the sod gene, either by allelic exchange or by transposon mutagenesis (data not shown).

Finally, we employed a proteomic comparison of wild-type and mutant spirochetes to identify L. biflexa proteins whose expression may be altered due to the loss of the Bat proteins. Two-dimensional differential gel electrophoresis of protein lysates from the wildtype and the $\triangle b a t A B D$ strain identified HtpG as the sole protein in the $\triangle b a t A B D$ strain that had significantly reduced levels compared to the wild-type (Figure 7). Altered levels of HtpG were detected in the membrane-associated protein fraction, but not the soluble fraction (data not shown), although HtpG does not have any recognizable signal or lipidation sequences. However, Lo et al. also reported that HtpG associated with the membrane fraction in their analyses of temperature effects on protein levels in 


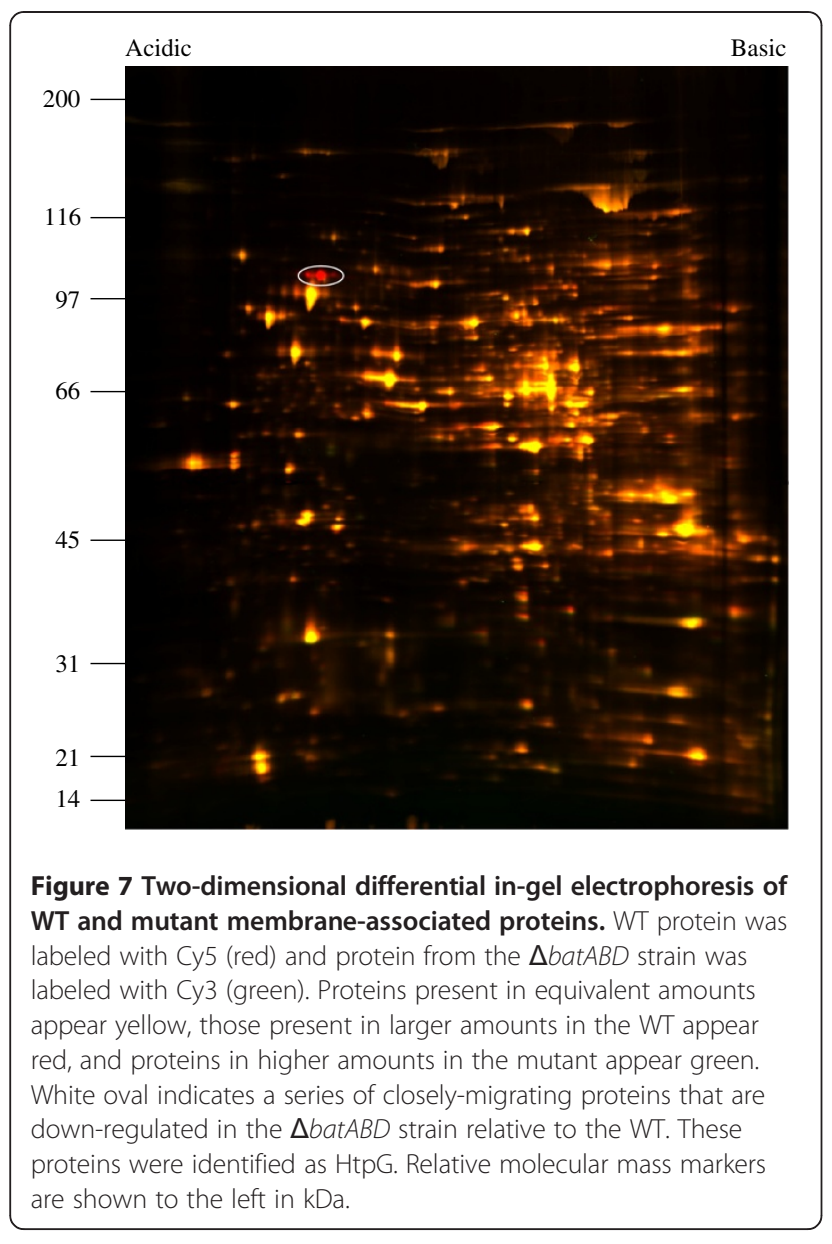

L. interrogans [24]. In our analysis, HtpG was downregulated approximately 4 -fold in the $\triangle$ batABD mutant relative to the WT, and this decrease corresponded to the 3.8-fold decrease in $h t p G$ transcript levels observed by qRT-PCR (Figure 3), discussed above. Although HtpG protein is lower in the mutant, this variation did not produce a phenotype in the conditions tested here.

\section{Conclusions}

L. biflexa has a relatively small repertoire of enzymes for defense against ROS, and it may depend on the activities of Sod and KatG to survive oxidative assault. During in vitro growth, bat transcript levels are relatively low and deletion of the bat loci did not detectably alter morphology, growth rate, or the ability to survive oxidative stress. Despite the proposed role for the Bat proteins in directly combating oxidative damage in spirochetes, the data presented here do not support this. Although we cannot exclude a role for the Bat proteins in sensing oxidative stress in L. biflexa, perhaps as a signaling complex in the periplasm, Bat function remains elusive.

\section{Methods}

Bacterial strains used in this study

L. biflexa serovar Patoc strain Patoc I (kindly provided by Dr. Dave Haake and Dr. Marija Pinne) was cultured at $30^{\circ} \mathrm{C}$ with shaking at $150 \mathrm{RPM}$ in EMJH medium (Fisher Scientific, Pittsburgh, PA) [41,42]. Plating medium included $1.2 \% \mathrm{wt} / \mathrm{vol}$ Noble agar (final concentration) (Fisher Scientific) and plates were incubated at $30^{\circ} \mathrm{C}$, inverted and sealed with parafilm. Kanamycin, when needed, was added to the medium at a final concentration of $20 \mu \mathrm{g} / \mathrm{mL}$. Escherichia coli strains TOP10 (Invitrogen, Carlsbad, CA) or NEB5 $\alpha$ (New England Biolabs, Ipswich, MA) were used for all plasmid manipulations.

\section{Construction of $L$. biflexa mutant strains}

Transformation of $L$. biflexa followed the protocol of Louvel and Picardeau [43]. L. biflexa deletion mutants were constructed by allelic exchange with the kanamycin-resistance marker driven by the borrelial $f l g B$ promoter [13]. Proof-reading polymerases Vent (New England BioLabs) or the Expand Long Template PCR System (Roche Applied Science, Indianapolis, IN) were used for fragment amplification according to the manufacturer's recommendations and the fidelity of amplification was confirmed by double-stranded sequencing. Primers used for plasmid construction are shown in Table 1 . The region encompassing the batABD locus and surrounding sequences was PCRamplified using primers Lb.htpG.F and Lb.II0014.RC, yielding a 6,113 bp fragment that was then cloned into pCR-XL-TOPO (Invitrogen). Inverse PCR was used to delete the batABD genes using primers batKO.F.NheI and batAKO.RC.NheI, which incorporated NheI restriction enzyme sites for self-ligation of the resulting product. NheI restriction enzyme sites were also incorporated onto the kanamycin-resistance cassette by PCR amplification using primers Pflg.NheI.F and Tkan.NheI.RC. Both the pTopoXL:: $\triangle$ batABD and the $f \lg B_{P}-k a n$ cassette were digested with NheI and ligated together to create the allelic exchange vector $\mathrm{p} \triangle \mathrm{ABD} 1-\mathrm{kn}$. A similar strategy was used to create the allelic exchange construct for batA (p $\Delta$ batA-kn) using primers batB.seq1.F and Lb.II0013/14.PCR1.RC to amplify a 2,565 bp fragment containing batA. Inverse PCR with primers batAKO.F.NheI and batAKO.RC. NheI were used to delete the coding region of batA and engineer the restriction enzyme sites needed to insert the kanamycin-resistance cassette. The deletions of the respective bat genes in the mutant strains of L. biflexa were confirmed by Southern blot analysis of total genomic DNA digested with the restriction enzymes NdeI and PstI, as previously described $[44,45]$. Primers used for probe amplification are listed in Table 1. 
Table 1 Oligonucleotides used in this study

\begin{tabular}{|c|c|c|}
\hline Oligonucleotide & Sequence $\left(5^{\prime}-3^{\prime}\right)$ & Function \\
\hline Lb.htpG.F & GTCTACATTGAGATGGATGTGG & Amplification of bat $A B D+$ flanking sequences \\
\hline Lb.II0014.RC & CAGACCAATTACTCAAATGC & Amplification of bat $A B D+$ flanking sequences \\
\hline batB.seq1.F & CAGCGATGGACTCTAGAAAATC & Amplification of batA + flanking sequences \\
\hline Lb.II0013/14.PCR1.RC & CTGTTGTTATCTTCGCTTCAC & Amplification of batA + flanking sequences \\
\hline batAKO.RC.Nhel & ${ }^{a}$ gctagcGTTAGGTTATAAAATCCTITITG & Construction of allelic-exchange plasmids \\
\hline batKO.F.Nhel & gctagcCATATGCAAGCTGAAGAAAAAGG & Construction of $\triangle b a t A B D$ allelic-exchange plasmid \\
\hline batAKO.F. Nhel & gctagcATGGAAACAAATACGGTTATTTAC & Construction of $\Delta b a t A$ allelic-exchange plasmid \\
\hline Pflg.Nhel.F & gctagcTACCCGAGCTTCAAGGAAGATT & Amplification of kan \\
\hline Tkan.Nhel.RC & gctagcGAGCTAGCGCCGTCCCGTCAA & Amplification of kan \\
\hline Lb.batA.F & CTGGGAACTGAGTTTCTTGG & Amplification of batA probe \\
\hline Lb.batA.RC & CTCGTCCTATCATCCTACAGG & Amplification of batA probe \\
\hline Lb.batB.RC & CCAGAACCAATCCAATGGGC & Amplification of batB/D probe \\
\hline batD.PCR1.RC & GAATTCGACTTCGACCGAG & Amplification of batB/D probe \\
\hline flaB.F.qPCR & CTGCTTACAGGAGCGTTGCT & qPCR primer \\
\hline flaB.RC.qPCR & TGGTGCATGTTAGCTCCAATATG & qPCR primer \\
\hline flab.Lb.Probe & ${ }^{b}$ ACTCAACCCAACTGCTAGTATGTGGTT & qPCR probe \\
\hline batA.F.qPCR & AGGAGCCGCATACTTACAATCC & qPCR primer \\
\hline batA.RC.qPCR & GGATGTACCGGCTATCAGTTCAT & qPCR primer \\
\hline batA.probe & ${ }^{b}$ CTTTCAAGTGACCGTTTGCCT & qPCR probe \\
\hline batB.F.qPCR & CCTGGAACCGGGAAAGGT & qPCR primer \\
\hline batB.RC.qPCR & ATCACATTGTCGCCGTAAGGT & qPCR primer \\
\hline batB.probe & ${ }^{b} \mathrm{CTTTGTTACTTACGATTCTAATTGGTAG}$ & qPCR probe \\
\hline batD.F.qPCR & TGTCGCTATGGTAGAAGGATTCG & qPCR primer \\
\hline batD.RC.qPCR & TGCGGACACTCCCTGTTTC & qPCR primer \\
\hline batD.probe & ${ }^{\text {DAAAGAAATTACTTCCTCTCTGAGTTCTTAG }}$ & qPCR probe \\
\hline htpG.F.qPCR & TITTCGGGAGCAACTGACTTC & qPCR primer \\
\hline htpG.RC.qPCR & TCCTAGTCCAAAATGGCCTATGAT & qPCR primer \\
\hline htpG.probe & ${ }^{b}$ CCAAACAGTACCAGAACACAGAAAATAAGGCAG & qPCR probe \\
\hline phoR.F.qPCR & CGTTTGATTCGCAGGGTGAT & qPCR primer \\
\hline phoR.RC.qPCR & TTAGGCTCCAAGGCAGATAAAATT & qPCR primer \\
\hline phoR.probe & ${ }^{b}$ AAGCGGTGCAAACTGCACTCAATTITG & qPCR probe \\
\hline
\end{tabular}

${ }^{a}$ Restriction enzyme sequences designated in lower case letters.

${ }^{b}$ TaqMan probes were labeled at the 5'-end with FAM (6-carboxyfluorescein) and at the $3^{\prime}$-end with TAMRA (6-carboxytetramethylrhodamine).

RNA isolation and quantitative RT-PCR analysis

Total RNA was isolated from $10 \mathrm{~mL}$ cultures of exponentially growing $L$. biflexa cells using TRIzol reagent (Invitrogen). Cells were pelleted at 7,000 RPMs in $15 \mathrm{~mL}$ Falcon 2059 tubes and the pellet resuspended in $5.0 \mathrm{~mL}$ TRIzol. After incubation at room temperature for 2.5 min with vigorous shaking, $1 \mathrm{~mL}$ of chloroform was added, mixed and incubated for a further $2.5 \mathrm{~min}$. The suspension was centrifuged again and the aqueous phase removed to a new Falcon tube and the RNA precipitated by addition of $5 \mathrm{~mL}$ isopropanol. Following a 10 minute incubation (room temperature), RNA was pelleted, washed in $75 \%$ ethanol and dissolved in $100 \mu \mathrm{L}$ of RNase-free water. DNA was removed by treating with Turbo DNase (Ambion, INC. Austin, TX) following the manufacturer's recommendations.

RNA was converted to cDNA using the High-Capacity cDNA Reverse Transcription kit (Applied Biosystems, Foster City, CA); reaction mixtures consisted of $1 \mu \mathrm{g}$ RNA and were converted to cDNA per the manufacturer's recommendations. The cDNA samples were diluted 1:20 with water and $2 \mu \mathrm{L}$ used for subsequent quantitative PCR (qPCR) reactions. All samples were analyzed in triplicate. TaqMan Universal PCR Master 
Mix kit (Applied Biosystems) and PCR conditions were as previously described [46]. L. biflexa genomic DNA ranging from $10^{6}$ cells to 10 cells (in 10 -fold serial dilutions) was used to generate a standard curve using the $\mathrm{Ct}$ values from the $f l a B$ primer/probe set. This standard curve was then used to interpolate the number of transcript copies from the $\mathrm{Ct}$ values generated from gene-specific primer/probe sets. The resulting transcript levels were then normalized to $10^{4}$ copies of flaB transcript. Negative controls lacking reverse transcriptase were included to demonstrate that all genomic DNA had been degraded and did not contribute to the signal.

\section{Electron microscopy, growth rate analysis and oxidative stress assays}

Bacterial suspensions from cultures grown in EMJH media were prepared for scanning electron microscopy (SEM) essentially as described previously [47]. Samples were lightly sputtered with iridium and examined on a model SU-8000 scanning electron microscope operated at $2 \mathrm{kV}$ (Hitachi High Technologies America, Pleasanton, CA). Images were digitized using the on-board frame card according to the manufacturer's specifications.

For transmission electron microscopy (TEM), bacteria were prepared as described previously for imaging by microwave-assisted processing [48]. Grids were examined using a model H-7500 transmission electron microscope, operated at $80 \mathrm{kV}$ (Hitachi). Digital images were captured and recorded using a model HR100 camera system (Advanced Microscopy Techniques, Danvers, MA).

Growth rate comparisons were performed in quadruplicate. Five $\mathrm{mL}$ cultures were inoculated at $10^{5}$ cells $/ \mathrm{mL}$ from a starter culture grown to between $5 \times 10^{8}$ to $1 \times$ $10^{9}$ cells $/ \mathrm{mL}$, as determined by counting with PetroffHauser counting chambers. All cultures were incubated at $30^{\circ} \mathrm{C}$; aerated cultures were shaken at 150 RPM. Cell densities were measured by optical density at $420 \mathrm{~nm}$ in a spectrophotometer.

Co-growth comparisons of wild-type and mutant strains were similarly tested with each strain inoculated at $10^{5}$ cells $/ \mathrm{mL}$ in the same culture (for a combined concentration of $2 \times 10^{5}$ cells $/ \mathrm{mL}$ ). Aliquots were removed daily from triplicate cultures, counted and diluted appropriately for colony formation on non-selective EMJH agar plates. PCR was performed on 24-30 colonies per plate to enumerate wild-type and mutant cells by amplifying a fragment of batB (wild-type) and the kanamycinselectable marker (mutant).

Oxidative stress assays were also performed similarly. Peroxide-treated cultures were first diluted to $10^{3}$ cells/ $\mathrm{mL}$ and peroxides were then added at specified concentrations and incubated for approximately $2 \frac{1}{2}$ hours, after which $100 \mu \mathrm{L}$ samples were removed from each culture and spread on EMJH agar plates. After 4-6 days of incubation at $30^{\circ} \mathrm{C}$, plates were removed and colony counts used to calculate viable cells. A similar strategy was followed for assessing whether an oxidative stress response could be induced in L. biflexa; quadruplicate cultures of $10^{3}$ cells $/ \mathrm{mL}$ were exposed to a sublethal level of $\mathrm{H}_{2} \mathrm{O}_{2}$ $(1 \mu \mathrm{M})$ for $3 \mathrm{hrs}$ with aeration, followed by the addition of specified concentrations of peroxide and a further incubation for 3 hours. Aliquots of $100 \mu \mathrm{L}$ were removed and spread on EMJH agar plates to determine viable cell counts. Superoxide sensitivity was determined by diluting triplicate cultures to $5 \times 10^{6}$ cells $/ \mathrm{mL}$ and exposing to various concentrations of the superoxide-generating molecule paraquat (Sigma-Aldrich, St. Louis, MO) with incubation for 24 hrs. Cell viability was determined by counting motile cells using a Petroff-Hauser chamber with darkfield microscopy. To determine if $L$. biflexa produces an oxidative stress response to superoxide, triplicate cultures of $5 \times 10^{6}$ cells $/ \mathrm{mL}$ were pre-exposed to 0.5 $\mu \mathrm{M}$ paraquat for $2.5 \mathrm{hrs}$ followed by addition of specific concentrations of paraquat. Cultures were further incubated for $24 \mathrm{hrs}$ and cell viability assessed as described above.

\section{Two-dimensional differential in-gel electrophoresis (2D-DIGE) and protein identification}

L. biflexa isolates were grown to a cell density of $\sim 1 \times 10^{9}$ cells $/ \mathrm{ml}$ and harvested by centrifugation $(10,000 \times g$, $10 \mathrm{~min}, 23^{\circ} \mathrm{C}$ ). Cell pellets were rinsed in PBS and lysed in PBS supplemented with $1 \mathrm{X}$ Complete Protease Inhibitor (Roche Applied Science) by 3 passes through a French pressure cell $\left(16,000 \mathrm{lb} / \mathrm{in}^{2}\right)$. Cell lysates were further fractionated into soluble and membrane-associated proteins by ultracentrifugation $\left(100,000 \times g 1 \mathrm{~h}, 4^{\circ} \mathrm{C}\right)$. The membrane-associated protein pellet was rinsed with PBS and suspended in PBS+PI with the aid of a glass tissue homogenizer (Kontes Glass Co.,Vineland, NJ). Protein concentrations were determined by a modified Lowry protein assay with bovine serum albumin as a standard.

For DIGE analysis of membrane-associated proteins, $50 \mathrm{ug}$ of L. biflexa wild-type or the $\triangle$ bat $A B D$ isolate was labeled with either 400 pmol Cy3 or Cy5 (CyDye minimal dye labeling kit, GE Healthcare) for $30 \mathrm{~min}$ on ice. As an internal control, a mixture of $25 \mathrm{ug}$ of the wildtype and 25 ug of the $\triangle$ batABD samples were labeled with $\mathrm{Cy} 2$ for $30 \mathrm{~min}$ on ice. All labeling reactions were performed in DIGE labeling solutions consisting of $7 \mathrm{M}$ Urea, 2M Thiourea, and 4\% CHAPS in $10 \mathrm{mM}$ Tris ( $\mathrm{pH}$ 8.5). The labeling reaction was quenched by adding $1 \mathrm{ul}$ of $10 \mathrm{mM}$ lysine and incubating for $10 \mathrm{~min}$ on ice. To ensure that observed differences were not due to artifacts from preferential dye binding to proteins, several coupled samples were labeled by dye switching. 
Labeled proteins were stored at $-20^{\circ} \mathrm{C}$ in the dark until isoelectric focusing.

Cy-dye labeled samples for comparison were mixed and DTT and IPGphore 3-10 buffer were added at final concentrations of $100 \mathrm{mM}$ and $1.0 \%$, respectively. The volume of each set was brought to $350 \mathrm{ul}$ with isoelectric focusing solution $\mathrm{C}_{4} \mathrm{TT}$ [49] and applied to $18 \mathrm{~cm}$ 3-10 non-linear IPG strips (GE Healthcare). Strips were focused using the following parameters: $12 \mathrm{hr}$ rehydration, $500 \mathrm{~V}$ for $1 \mathrm{hr}, 1000 \mathrm{~V}$ for $1 \mathrm{hr}, 1500 \mathrm{~V}$ for $1 \mathrm{hr}$, $4000 \mathrm{~V}$ for $1 \mathrm{hr}$, and $8000 \mathrm{~V}$ for $60,000 \mathrm{Vhr}$. Once focusing was complete, strips were stored at $-80^{\circ} \mathrm{C}$ until equilibrated and separated in the second dimension by standard SDS-PAGE using 8-16\% gradient gels (Jule, Inc., Milford, CT) [49].

After separation of DIGE-labeled strips by SDS-PAGE, gels were scanned in the glass plates using a three laser Typhoon 9400 variable mode imager (GE Healthcare, Piscataway, NJ) at 200 microns. Differences in protein spots were quantified using DeCyder 2-D Differential Analysis Software v7.2. Protein spots of interest were excised and processed for mass spectrometry as previously described [49]. Dried peptides were sent to the Protein Chemistry section of the NIAID Research Technologies Branch, NIH for identification as described below.

The recovered peptides were re-suspended in $5 \mathrm{ul}$ of Solvent A (0.1\% formic acid, $2 \%$ acetonitrile, and $97.9 \%$ water). Prior to mass spectrometry analysis, the re-suspended peptides were chromatographed directly on column, without trap clean-up. The bound peptides were separated at $500 \mathrm{nl} / \mathrm{min}$ generating $80-120$ Bar pressure, using an AQ C18 reverse phase media ( 3 u particle size and $200 \mathrm{u}$ pore) packed in a pulled tip, nano-chromatography column $(0.100 \mathrm{~mm}$ ID $\times 150 \mathrm{~mm} \mathrm{~L})$ from Precision Capillary Columns, San Clemente, CA. The chromatography was performed in-line with an LTQVelos Orbitrap mass spectrometer (ThermoFisher Scientific, West Palm Beach, FL) and the mobile phase consisted of a linear gradient prepared from solvent A and solvent B $(0.1 \%$ formic acid, $2 \%$ water, and 97.9\% acetonitrile) at room temperature. Nano LC-MS (LC-MS/MS) was performed with a ProXeon EasynLC II multi-dimensional liquid chromatograph and temperature controlled Ion Max Nanospray source (ThermoFisher Scientific) in-line with the LTQ-Velos Orbitrap mass spectrometer.

Mass calibration was performed as needed with the positive ion Cal Mix prepared as described by ThermoScientific and monitored by routine analysis of a 10 femtomole stock sample of BSA digest. Typical acceptable results for this analysis would yield a $2800-3300$ Mascot score, $75-85 \%$ coverage and $0-+/-4$ ppm error when submitted to the Mascot server using Proteome Discoverer 1.3 using the Swiss Prot-Trembl data base.
Computer controlled data dependent automated switching to MS/MS by Xcalibur 2.1 software was used for data acquisition and provided the peptide sequence information. Data processing and databank searching were performed with PD 1.3 and Mascot software (Matrix Science, Beachwood, $\mathrm{OH})$.

\section{Additional file}

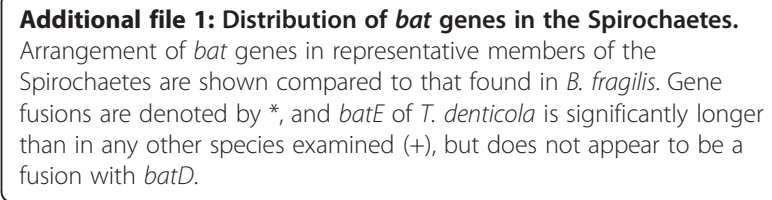

\section{Competing interests}

The authors declare that they have no competing interests.

\section{Authors' contributions}

PES, MP, and PAR conceived of the study. PES carried out the molecular genetic studies, growth curve analyses, and drafted the manuscript. JAC carried out the proteomic experiments. DWD performed the microscopy. $\mathrm{HHS}$ and AS participated in the molecular genetic studies. MP participated in the design of the study and the molecular genetic studies. PAR participated in the manuscript and experimental design and helped to draft the manuscript. All authors read, edited and approved the final manuscript.

\section{Acknowledgements}

The authors gratefully acknowledge the generous gifts of strains and advice from David Haake and Marije Pinne. We also thank Joe Hinnebusch and Frank Gherardini for critical reading of the manuscript; Dan Sturdevant, Kevin Lawrence and Julie Boylan for technical advice and helpful discussions, Jeff Skinner at Bioinformatics and Computational Biosciences Branch for statistical analysis, and Scott Samuels' lab for technical advice on RNA isolation. This research was supported by the Intramural Research Program of the NIH, NIAID.

\section{Author details}

${ }^{1}$ Laboratory of Zoonotic Pathogens, Rocky Mountain Laboratories, National Institute of Allergy and Infectious Diseases, National Institutes of Health, 903 South 4th St, Hamilton, Montana 59840, US. ${ }^{2}$ Laboratory of Persistent Viral Diseases, Rocky Mountain Laboratories, National Institute of Allergy and Infectious Diseases, National Institutes of Health, 903 South 4th St, Hamilton, Montana 59840, US. ${ }^{3}$ Research Technologies Branch, Rocky Mountain Laboratories, National Institute of Allergy and Infectious Diseases, National Institutes of Health, 903 South 4th St, Hamilton, Montana 59840, US. ${ }^{4}$ Institut Pasteur, Unité Biologie des Spirochètes, 25 rue du Dr. Roux, Paris 75015, France.

Received: 30 July 2012 Accepted: 10 December 2012 Published: 13 December 2012

\section{References}

1. Storz G, Spiro S: Sensing and responding to reactive oxygen and nitrogen species. In Bacterial stress responses. Secondth edition. Edited by Storz G, Hengge R. Washington, DC: ASM Press; 2011:157-173.

2. Nascimento AL, Ko Al, Martins EA, Monteiro-Vitorello CB, Ho PL, Haake DA, Verjovski-Almeida S, Hartskeerl RA, Marques MV, Oliveira MC, et al: Comparative genomics of two Leptospira interrogans serovars reveals novel insights into physiology and pathogenesis. J Bacterio/ 2004, 186(7):2164-2172.

3. Murgia R, Garcia R, Cinco M: Leptospires are killed in vitro by both oxygendependent and -independent reactions. Infect Immun 2002, 70(12):7172-7175.

4. Tang YP, Dallas MM, Malamy MH: Characterization of the batl (Bacteroides aerotolerance) operon in Bacteroides fragilis: isolation of a B. Fragilis mutant with reduced aerotolerance and impaired growth in in vivo model systems. Mol Microbiol 1999, 32(1):139-149. 
5. Dieppedale J, Sobral D, Dupuis M, Dubail I, Klimentova J, Stulik J, Postic G, Frapy E, Meibom KL, Barel M, Charbit A: Identification of a putative chaperone involved in stress resistance and virulence in Francisella tularensis. Infect Immun 2011, 79(4):1428-1439.

6. Eshghi A, Lourdault K, Murray GL, Bartpho T, Sermswan RW, Picardeau M, Adler B, Snarr B, Zuerner RL, Cameron CE: Leptospira interrogans catalase is required for resistance to $\mathrm{H} 2 \mathrm{O} 2$ and for virulence. Infect Immun 2012, 80(11):3892-3899.

7. Bulach DM, Zuerner RL, Wilson P, Seemann T, McGrath A, Cullen PA, Davis J, Johnson M, Kuczek E, Alt DP, et al: Genome reduction in Leptospira borgpetersenii reflects limited transmission potential. Proc Natl Acad Sci USA 2006, 103(39):14560-14565.

8. Picardeau M, Bulach DM, Bouchier C, Zuerner RL, Zidane N, Wilson PJ, Creno S, Kuczek ES, Bommezzadri S, Davis JC, et al: Genome sequence of the saprophyte Leptospira biflexa provides insights into the evolution of Leptospira and the pathogenesis of leptospirosis. PLoS One 2008, 3(2):e1607.

9. Ren SX, Fu G, Jiang XG, Zeng R, Miao YG, Xu H, Zhang YX, Xiong H, Lu G, Lu LF, et al: Unique physiological and pathogenic features of Leptospira interrogans revealed by whole-genome sequencing. Nature 2003, 422(6934):888-893.

10. Lee JO, Rieu P, Arnaout MA, Liddington R: Crystal structure of the $A$ domain from the alpha subunit of integrin CR3 (CD11b/CD18). Cell 1995, 80(4):631-638

11. Whittaker CA, Hynes RO: Distribution and evolution of von Willebrand/ integrin A domains: widely dispersed domains with roles in cell adhesion and elsewhere. Mol Biol Cell 2002, 13(10):3369-3387.

12. Allan RK, Ratajczak T: Versatile TPR domains accommodate different modes of target protein recognition and function. Cell Stress Chaperones 2011, 16(4):353-367.

13. Bono JL, Elias AF, Kupko JJ III, Stevenson B, Tilly K, Rosa P: Efficient targeted mutagenesis in Borrelia burgdorferi. J Bacteriol 2000, 182(9):2445-2452.

14. Seshadri R, Myers GS, Tettelin H, Eisen JA, Heidelberg JF, Dodson RJ, Davidsen TM, DeBoy RT, Fouts DE, Haft DH, et al: Comparison of the genome of the oral pathogen Treponema denticola with other spirochete genomes. Proc Natl Acad Sci USA 2004, 101(15):5646-5651.

15. Christman MF, Morgan RW, Jacobson FS, Ames BN: Positive control of a regulon for defenses against oxidative stress and some heat-shock proteins in Salmonella typhimurium. Cell 1985, 41(3):753-762.

16. Demple B, Halbrook J: Inducible repair of oxidative DNA damage in Escherichia coli. Nature 1983, 304(5925):466-468.

17. Paster BJ, Dewhirst FE, Weisburg WG, Tordoff LA, Fraser GJ, Hespell RB, Stanton TB, Zablen L, Mandelco L, Woese CR: Phylogenetic analysis of the spirochetes. J Bacteriol 1991, 173(19):6101-6109.

18. Snider J, Houry WA: MoxR AAA+ ATPases: a novel family of molecular chaperones? J Struct Biol 2006, 156(1):200-209.

19. Sato T, Minagawa S, Kojima E, Okamoto N, Nakamoto H: HtpG, the prokaryotic homologue of $\mathrm{Hsp} 90$, stabilizes a phycobilisome protein in the cyanobacterium Synechococcus elongatus PCC 7942. Mol Microbiol 2010, 76(3):576-589.

20. Steeves $\mathrm{CH}$, Potrykus J, Barnett DA, Bearne SL: Oxidative stress response in the opportunistic oral pathogen Fusobacterium nucleatum. Proteomics 2011, 11(10):2027-2037.

21. Thomas JG, Baneyx F: ClpB and HtpG facilitate de novo protein folding in stressed Escherichia coli cells. Mol Microbiol 2000, 36(6):1360-1370.

22. Watanabe S, Kobayashi T, Saito M, Sato M, Nimura-Matsune K, Chibazakura T, Taketani S, Nakamoto H, Yoshikawa H: Studies on the role of HtpG in the tetrapyrrole biosynthesis pathway of the cyanobacterium Synechococcus elongatus PCC 7942. Biochem Biophys Res Commun 2007, 352(1):36-41.

23. Lo M, Bulach DM, Powell DR, Haake DA, Matsunaga J, Paustian ML, Zuerner $R L$, Adler B: Effects of temperature on gene expression patterns in Leptospira interrogans serovar Lai as assessed by whole-genome microarrays. Infect Immun 2006, 74(10):5848-5859.

24. Lo M, Cordwell SJ, Bulach DM, Adler B: Comparative transcriptional and translational analysis of leptospiral outer membrane protein expression in response to temperature. PLOS Negl Trop Dis 2009, 3(12):e560.

25. Lo M, Murray GL, Khoo CA, Haake DA, Zuerner RL, Adler B: Transcriptional response of Leptospira interrogans to iron limitation and characterization of a PerR homolog. Infect Immun 2010, 78(11):4850-4859.

26. Matsunaga J, Lo M, Bulach DM, Zuerner RL, Adler B, Haake DA: Response of Leptospira interrogans to physiologic osmolarity: relevance in signaling the environment-to-host transition. Infect Immun 2007, 75(6):2864-2874.
27. Patarakul K, Lo M, Adler B: Global transcriptomic response of Leptospira interrogans serovar Copenhageni upon exposure to serum. BMC Microbiol 2010, 10:31

28. Qin JH, Sheng YY, Zhang ZM, Shi YZ, He P, Hu BY, Yang Y, Liu SG, Zhao GP, Guo XK: Genome-wide transcriptional analysis of temperature shift in L. interrogans serovar lai strain 56601. BMC Microbiol 2006, 6:51.

29. Xue F, Dong H, Wu J, Wu Z, Hu W, Sun A, Troxell B, Yang XF, Yan J: Transcriptional responses of Leptospira interrogans to host innate immunity: significant changes in metabolism, oxygen tolerance, and outer membrane. PLoS Negl Trop Dis 2010, 4(10):e857.

30. Greenberg JT, Demple B: A global response induced in Escherichia coli by redox-cycling agents overlaps with that induced by peroxide stress J Bacterio/ 1989, 171(7):3933-3939.

31. Greenberg JT, Monach P, Chou JH, Josephy PD, Demple B: Positive control of a global antioxidant defense regulon activated by superoxidegenerating agents in Escherichia coli. Proc Natl Acad Sci USA 1990, 87(16):6181-6185.

32. Walkup LK, Kogoma T: Escherichia coli proteins inducible by oxidative stress mediated by the superoxide radical. J Bacteriol 1989, 171(3):1476-1484.

33. Dubbs JM, Mongkolsuk S: Peroxiredoxins in bacterial antioxidant defense. Sub-cellular biochemistry 2007, 44:143-193.

34. Boylan JA, Lawrence KA, Downey JS, Gherardini FC: Borrelia burgdorferi membranes are the primary targets of reactive oxygen species. $\mathrm{Mol}$ Microbiol 2008, 68(3):786-799

35. Imlay JA, Linn S: Bimodal pattern of killing of DNA-repair-defective or anoxically grown Escherichia coli by hydrogen peroxide. J Bacteriol 1986, 166(2):519-527.

36. Austin FE, Barbieri JT, Corin RE, Grigas KE, Cox CD: Distribution of superoxide dismutase, catalase, and peroxidase activities among Treponema pallidum and other spirochetes. Infect Immun 1981, 33(2):372-379.

37. Banfi $E$, Cinco $M$, Dri P: Catalase activity among leptospires. Experientia 1981, 37(2):147-148.

38. Corin RE, Boggs $\mathrm{E}$, Cox CD: Enzymatic degradation of $\mathrm{H}_{2} \mathrm{O}_{2}$ by Leptospira. Infect Immun 1978, 22(3):672-675

39. Corin RE, Cox CD: Characterization of leptospiral catalase and peroxidase. Can J Microbiol 1980, 26(2):121-129.

40. Green SS, Goldberg HS, Blenden DC: Enzyme patterns in the study of Leptospira. Appl Microbiol 1967, 15(5):1104-1113.

41. Ellinghausen $\mathrm{HC} \mathrm{Jr}$, McCullough WG: Nutrition of Leptospira pomona and growth of 13 other serotypes: fractionation of oleic albumin complex and a medium of bovine albumin and polysorbate 80. Am J Vet Res 1965, 26:45-51.

42. Johnson RC, Harris VG: Differentiation of pathogenic and saprophytic leptospires. I. Growth at low temperatures. J Bacterio/ 1967, 94(1):27-31.

43. Louvel H, Picardeau M: Genetic manipulation of Leptospira biflexa. In Current Protocols in Microbiology. John Wiley \& Sons, Inc.; 2007:12E.14.11-12E.14.12.

44. Sambrook J, Fritsch EF, Maniatis T: Molecular Cloning. A Laboratory Manual. 2nd edition. Cold Spring Harbor, NY: Cold Spring Harbor Laboratory Press; 1989.

45. Stewart PE, Thalken R, Bono JL, Rosa P: Isolation of a circular plasmid region sufficient for autonomous replication and transformation of infectious Borrelia burgdorferi. Mol Microbiol 2001, 39(3):714-721.

46. Stewart PE, Bestor A, Cullen JN, Rosa PA: Tightly regulated surface protein of Borrelia burgdorferi is not essential to the mouse-tick infectious cycle. Infect Immun 2008, 76(5):1970-1978.

47. Dorward DW: Ultrastructural analysis of bacteria-host cell interactions. In Bacterial pathogenesis. 431st edition. Edited by DeLeo F, Otto M. Totowa, NJ: Humana Press; 2008:173-187 [Walker JM (Series Editor): Methods in Molecular Biology].

48. Howe D, Shannon JG, Winfree S, Dorward DW, Heinzen RA: Coxiella burnetii phase I and II variants replicate with similar kinetics in degradative phagolysosome-like compartments of human macrophages. Infect Immun 2010, 78(8):3465-3474.

49. Norwalk AJ, Nolder C, Clifton DR, Carroll JA: Comparative proteome analysis of subcellular fractions from Borrelia burgdorferi by NEPHGE and IPG. Proteomics 2006, 6(7):2121-2134.

doi:10.1186/1471-2180-12-290

Cite this article as: Stewart et al.: Characterization of the Bat proteins in the oxidative stress response of Leptospira biflexa. BMC Microbiology 2012 $12: 290$. 